This item was submitted to Loughborough's Research Repository by the author.

Items in Figshare are protected by copyright, with all rights reserved, unless otherwise indicated.

\title{
The effects of masculinity and suspect gender on perceptions of guilt
}

PLEASE CITE THE PUBLISHED VERSION

http://dx.doi.org/10.1002/acp.2823

\section{PUBLISHER}

(c) Wiley

\section{VERSION}

AM (Accepted Manuscript)

\section{PUBLISHER STATEMENT}

This work is made available according to the conditions of the Creative Commons Attribution-NonCommercialNoDerivatives 4.0 International (CC BY-NC-ND 4.0) licence. Full details of this licence are available at: https://creativecommons.org/licenses/by-nc-nd/4.0/

\section{LICENCE}

CC BY-NC-ND 4.0

\section{REPOSITORY RECORD}

Ward, Charlotte, Heather D. Flowe, and Joyce E. Humphries. 2019. "The Effects of Masculinity and Suspect Gender on Perceptions of Guilt”. figshare. https://hdl.handle.net/2134/20186. 
RUNNING HEAD: MASCULINUTY AND PERCEPTIONS OF GUILT

The Effects of Masculinity and Suspect Gender on Perceptions of Guilt

Charlotte Ward, Heather Flowe, \& Joyce Humphries

University of Leicester

School of Psychology 


\begin{abstract}
This study investigated whether perceptions of guilt for both male and female suspects covaried with masculine physical appearance. In addition, the study tested whether the relationship between masculine physical appearance and perceptions of guilt was dependent upon whether the crime is stereotypically male perpetrated. Participants read one of three crime scenarios (burglary, child abuse and neglect, fraud and forgery) and evaluated the likelihood that suspects of varying masculine appearance committed the crime in question. Masculine physical appearance significantly affected guilt ratings across all crime types for both male and female suspects. Additionally, guilt ratings for male compared to female suspects were higher for burglary, a crime that was viewed as stereotypically male perpetrated by research participants. The results are discussed in relation to applied implications and future research directions.
\end{abstract}


The Effects of Masculinity and Suspect Gender on Perceptions of Guilt

Ana Cardona was convicted in 1992 of killing her three-year-old son and was consequently given the death penalty. The prosecution attempted to "de-feminise" her by highlighting her lesbian sexual orientation and portraying her dress and demeanour as "manly" (Streib, n.d.). Criminological theories have long been dominated by the view that crime is an activity perpetuated by males, especially those who have an excess of masculine attributes, such as dominance and aggression (Carlen, 1985). In keeping with this portrayal, some have argued that the increase in female offending seen in recent years is attributable to women adopting more masculine traits and behaviours (Weiler, 1999). Female offenders, especially if they have been convicted of a violent offense, also perceive themselves as having more masculine traits than female non-offenders (Herrington \& Nee, 2005). The view that crime is mainly a masculine preoccupation raises the following research question: If a woman such as Ana Cardona is perceived as above average in masculine appearance compared to other women, will this affect people's assessments of her guilt all other things being equal?

We hypothesised in the present study that people's assessments of a woman's guilt are influenced by the extent to which she appears masculine. In particular, the argument is that masculine physical appearance can activate criminal stereotypes, which in turn bias people's judgments about a suspect's guilt. Previous work has demonstrated that faces rated high on perceived criminal appearance are more likely to be remembered (MacLin \& MacLin, 2004; c.f. Yarmey, 1993) and identified from criminal lineups (Flowe \& Humphries, 2010). More recently, masculine appearance has also been linked to identification outcomes. Turner (2007) demonstrated that the rate at which a male suspect is identified from a lineup is positively associated with having a masculine physical appearance. Moreover, people 
overwhelmingly report that the typical criminal perpetrator is "male" when asked to describe what they think a criminal looks like (Madriz, 1997; O'Connor, 1984; Reed \& Reed, 1973). Taken together, these results suggest that masculinity is a component of the criminal stereotype, and therefore, can influence people's impressions of criminal suspects. Only one study (unpublished) to our knowledge has examined the relationship between masculine physical appearance and perceptions of guilt with female suspects. Bustamante, Herrera and MacLin (2001) tested whether females who possess more stereotypically masculine physical traits were more likely to be viewed as criminal compared to less masculine females. Participants were presented with a photo lineup consisting of five faces previously rated as high in masculinity and a sixth face rated as low in masculinity. The instructions given to participants stated that the police believed one of the individuals in the lineup had recently committed an armed robbery, and the participant was to indicate which individual they believed was the robber. Results indicated that the face in the lineup with the lowest masculinity rating was chosen most often. On the one hand, these results may indicate that women who appear high in masculinity are less likely to be chosen from a lineup. On the other hand, perhaps participants chose the least masculine looking woman simply because she stood apart from the other's in her physical appearance.

We further examined whether guilt perceptions co-vary with masculine physical appearance for female suspects. Similar to Bustamante and colleagues, our participants were given a type of crime and asked to evaluate the guilt of a person shown in a photograph. Unlike Bustamante and colleagues' seminal work, however, we did not allow participants to make relative comparisons across photographs. Instead, we had participants rate the guilt of individual faces that were systematically varied in terms of their masculine appearance. 
We were also interested in whether people's perceptions of guilt varied depending on people's stereotypes concerning the types of crimes that are committed by men versus women. Previous research suggests that people's expectations about a criminal perpetrator's physical appearance vary in relation to the type of criminal offense (Dumas \& Teste, 2006; Kulka \& Kessler, 1978; Macrae \& Shepherd, 1989; Shoemaker, South, \& Lowe, 1973; Sigall \& Ostrove, 1975; Skorinko \& Spellman, 2006; Stewart, 1980; Yarmey, 1993). Research finds, for example, that mock jurors are more likely to find a defendant guilty if he has a face that is representative of the type of crime in question (Dumas \& Teste, 2006; Macrae \& Shepherd, 1989; Shoemaker, et al., 1973). This research, however, has focused by and large on male suspects. One study that did examine whether people have stereotypes concerning perpetrator gender and crime found that people associate violent crimes and drug offenses with male perpetrators, whereas prostitution and shoplifting are associated with female perpetrators (Skorinko \& Spellman, 2006). In the present study, participants evaluated the guilt of a male or female suspect in relation to a specific crime, which varied in terms of whether the crime was considered as one that is stereotypically male perpetrated. Perhaps assessments of a female suspect's guilt depend not only on her physical appearance, but also on whether the crime seems to require a high degree of masculine behaviour on the part of the culprit. If this is the case, women with a more masculine physical appearance will be found guilty more often than their counterparts, but only when the crime is stereotypically male perpetrated. On the other hand, masculine appearance by itself may be sufficient for criminal stereotype activation. If this is the case, then a person will be found guilty less often if they do not have a masculine appearance, regardless of preconceptions regarding the type of culprit who would commit a given criminal act. 
With respect to the face stimuli employed, we measured several dimensions of physical appearance in addition to masculinity. First, physical attractiveness was measured because it has been shown that physically attractive people are less likely to be rated as guilty of committing a criminal act compared to unattractive people (Bull, 1979; Saladin, Saper \& Breen, 1988; Hodgkiss \& Handy, 2007.; Mocan \& Tekin, 2006). Second, another physical attribute that we measured was criminal appearance. Macrae and Shepherd (1989) found that faces with a criminal appearance were rated higher on guilt, even after controlling for physical attractiveness. Additionally, Flowe and Humphries (2010) found in a random sample of police lineups that criminal appearance was a stronger predictor of mock witness identifications than either lineup member similarity or face distinctiveness. Third, the distinctiveness of the faces was measured. Previous research has found that not only are faces which are perceived to be more distinctive remembered more easily (Deffenbacher, Johanson, Vetter, \& O'Toole, 2000), but that faces rated in high in criminality are considered to be more distinctive than those low in criminality (MacLin \& MacLin, 2004).

In measuring physical attractiveness, criminal appearance, and distinctiveness we sought to collect a set of faces for each gender that differed predominately in terms of their masculine appearance. By so doing, we were able to test whether masculine appearance influenced guilt perceptions over and above other physical traits that have been associated with guilt.

\section{Present Study Hypotheses}

Based on the literature reviewed, the following predictions were tested:

1. Masculine appearance was predicted to affect perceptions of guilt for both male and female suspects. 
2. The relationship between masculinity and guilt perceptions were predicted to be stronger for crimes that are stereotyped as being predominately committed by male perpetrators.

\section{Method}

\section{Participants}

In total, 151 participants were recruited (30 male and 121 female) with an age range of 19-50 for males (mean $=30.8)$ and $18-77$ for females $($ mean $=30.0)$. The sample was predominately Caucasian (84.1\% identified as White British).

\section{Design}

The experiment employed a 3 (masculine appearance) x2 (suspect gender) x3 (crime type) mixed design. The independent variables were masculine physical appearance (low, moderate or high), "suspect" gender (male or female), and crime type (strong-stereotyped male crime, weak-stereotyped male crime, or gender neutral). Masculine physical appearance was a within participants factor, whereas the other variables were controlled between participants. The dependent variable was evaluation of the suspects' guilt, as measured by guilt ratings on a 7-point Likert-type scale.

\section{Materials}

The crime and photographic stimuli were pilot tested. The overall aim of the pilot was to identify which crime types and face stimuli were most suitable for the main study. The pilot study consisted of two phases. The purpose of the first phase was to determine which types of crime men and women are believed to commit, whilst the second phase gathered ratings 
of masculinity, attractiveness, distinctiveness and criminality for the purposes of selecting photographic stimuli.

\section{Crime Stimuli}

Ten crimes were selected from the Metropolitan Police Authority website (http://www.mpa.gov.uk/statistics/crime-stats/definitions/) as well as major crime categories used in substation and patrol district crime lists within the United States of America (http://www.sanantonio.gov/sapd/pdf/UCRcategories.pdf). The final crime types selected were robbery, burglary, rape, prostitution, child abuse and neglect, drug offenses, domestic violence, forgery and fraud, assault and murder. The legal definitions for each crime type were also obtained from the above sources, and were re-written in lay person's terms so participants were clear of what each crime type entailed in order to answer the questions provided.

In order to assess which crime types were stereotypically believed to be committed by men, women or equally likely to be committed by men and women, a group of pilot participants ( $\mathrm{N}=40,50 \%$ women, Mean age: $20.8,75 \%$ White British), were randomly assigned to indicate the percentage of offenses committed by men or to indicate the percentage of offenses that would be committed by women. Participants were randomly allocated to rate either men or women in order to control for the effect of an own gender bias on ratings. Participants were presented with each crime type, including its legal definition, and then asked to indicate what percentages of arrestees were male (or female).

Three stimulus crime types were selected based upon the results of independent samples t-tests. The distribution of crime types by gender is provided in Table 1. As shown, a 
significantly higher percentage of males were believed to have been convicted of rape, whereas a significantly higher percentage of females were believed to have been convicted of prostitution. The crime of child abuse and neglect was found to be equally applicable to both males and females as no significant difference between the groups was found. However, in order to avoid ceiling effects, the crimes that were found to have the second highest percentage difference in terms of gender were used. These crimes were burglary for the strong-stereotypic male crime and fraud/forgery for the weak-stereotypic male crime. Child abuse and neglect was chosen for the gender-neutral crime scenario ${ }^{1}$.

The crime scenario materials were based on the crime types identified from the pilot study. Each crime type was inputted into the LEXIS library database in order to examine real world cases and explore the way in which these cases were described. This allowed for a more realistic scenario to be constructed.

The crime scenarios were as follows:

\section{Burglary (strong-stereotyped male crime)}

On March $14^{\text {th }} 2008$ Mr. Brown of 124 Regent Street, rang the police to report that his home had been burgled. A neighbour had seen an individual enter the property through a downstairs window, after an unoccupied vehicle parked outside the house sparked concern. The individual was seen to be carrying items from the house to the parked vehicle. The neighbour then called out to the individual in order to identify if they were known the home owner. The individual was startled and proceeded to drive away in the vehicle with a number of items.

Fraud/Forgery (weak-stereotyped male crime)

On March $14^{\text {th }} 2008$ Officer Smith stopped a car due to a faulty light. The driver did not have a drivers licence and gave the officer an identification card. Upon giving the

\footnotetext{
${ }^{1}$ Participants reported males as more likely to be convicted of burglary $(M=78.50)$ than females $(M=22.75)$, $t(33.97)=12.19, p=.001$. Males were reported as more likely to be convicted of forgery and fraud $(\mathrm{M}=64.25)$ compared to females $(\mathrm{M}=42.50) t(38)=4.00, p=.001$. Females and males were viewed as equally likely to commit child abuse and neglect $(\mathrm{M}=56.60)$ compared to males $(\mathrm{M}=53.50), t(38)=.81, p=.43$.
} 
drivers name to dispatch, the officer learned that the driver did not have a valid driver's licence and that the identification card was forged. Upon searching the driver and the vehicle a national insurance card and other documentation were discovered which were also found to be counterfeit and being used to secure employment under a false identity.

\section{Child abuse and neglect (crime equally applicable to both genders)}

On March $14^{\text {th }} 2008$, a six month old baby was brought into hospital with a swollen leg, which X-rays revealed was due to a fracture to the left femur. No valid explanation could be provided as to how the injury occurred; therefore a social worker was called to the hospital. After conducting further tests old healing rib fractures (approximately one week old) and indicators of malnourishment were found. In the opinion of the examining doctor the injuries and symptoms in a child of this age were "highly specific for child abuse and neglect".

Photographic Face Stimuli.

The photographic facial stimuli for phase 2 of the pilot was comprised of 80 mug shots,

(40 male and 40 female), which were obtained from the Oklahoma Department of

Corrections website (http://www.doc.state.ok.us/). Using the offender search option, the criteria for selection were inputted. This was based on appearance and included specifying the offenders gender (male or female), age (25 years old $+/-5)$, and ethnicity (white). The age and ethnicity of the individuals within the photographic face stimuli were held constant in order to control for the effects of an own-race and own-age bias. Therefore, anticipating that the majority of participants would be college age and Caucasian, the initial pool of photographs was selected using these parameters. Other physical characteristics such as weight, tattoos or distinctive marks were not specified. After narrowing down the possible sample of photographs using these guidelines, the final set of mug shots was randomly selected.

In total, 6 photographs of men and 6 photographs of women were selected for the experiment. Within each gender, there were 3 levels of masculinity ( 2 faces that were 
relatively low in masculine appearance, 2 that were moderate, and 2 that were high). Masculinity was the only significant dimension on which the faces were to vary. For these purposes, another group of pilot participants ( $N=38,71 \%$ women, Mean age: $29.6,76 \%$ White British), rated the masculinity of the faces using a 7-point scale, anchored at 1 not at all masculine and 7 very masculine. The raters also evaluated the distinctiveness, attractiveness, and criminal appearance of the faces using this scale. The intent was to ensure that these aspects of physical appearance did not vary significantly across the faces. Measuring these aspects allowed for controlling other aspects of physical appearance that might affect guilt ratings. Faces were presented and evaluated one at a time to encourage the raters to make absolute ratings of these attributes.

The rating data were subjected to several paired samples t-tests until a set of pictures fitting the physical appearance selection criteria was found. Examples of the face stimuli appear in Figure 1.

\section{Procedure}

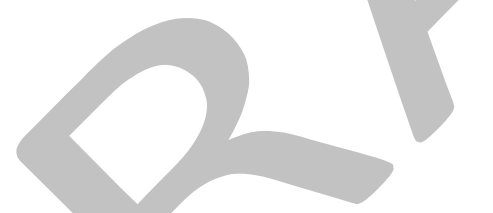

The experiment was computer-administered. The participant was presented with one of the three crime scenarios. Following the crime scenario, a photograph of a suspect for the crime in question was presented and the participant rated the suspect's guilt on a scale from 1 to 7, with "1" indicating "not at all guilty", and "7" indicating "completely guilty". Only one suspect was shown at a time. Participants had to rate the suspect shown before the next suspect was displayed. The presentation order of the photographic facial stimuli with respect to masculine appearance was counterbalanced across participants. Additionally, participants did not know in advance the number of faces that they would be rating. 


\section{Results}

The order in which participants evaluated the criminal suspects in terms of their masculine appearance did not influence guilt ratings in neither the female or male suspect conditions $\left(F^{\prime} s<1\right)$. Therefore, order was not considered further in the analyses that follow. The guilt ratings were analysed with a mixed ANOVA, with masculinity as the within participants factor, and suspect gender and crime type as the between participants factors; alpha was set to .05. The degrees of freedom were Greenhouse-Geisser corrected in analysing the masculinity effects. Significant results from the ANOVA were followed up with Bonferonni corrected t-tests.

Figure 2 presents the relationship between masculinity level and guilt perceptions for male and female suspects by crime type. Suspects were more likely to be perceived as guilty if they looked more masculine $\left(F(1.94,281.83)=13.19, p<.01, \eta_{p}{ }^{2}=.08\right)$, regardless of whether they were male or female. Suspects who were relatively less masculine in appearance were given lower guilt ratings than suspects who had a moderate masculine appearance $(M=3.43$ and $M=3.97$, respectively), $t(150)=-4.22, p<.001$, and compared to suspects who were relatively high in masculine appearance $(M=3.43$ and $M=4.10), t(150)$ $=-4.59, p<.001$. Suspects who were high versus moderate in masculine appearance did not significantly differ from each other with respect to guilt perceptions $(p=.29)$.

Suspect gender and crime type had an interactive effect on guilt ratings, $F(2,145)=4.07$, $p<.05, \eta_{p}{ }^{2}=.05$. As can be inferred from Figure 2 , the pattern of the data matches the pilot raters' estimates of the relative rate at which men and women commit burglary, child abuse and fraud (please see Table 1). Namely, participants seemed to be stereotyping the crime of burglary as a male crime, whereas the crimes of child abuse and fraud were viewed 
as less stereotypically male. To examine this further, the guilt ratings for the male and female suspects were compared within each crime category, using an alpha value of .016 (i.e., this was a Bonferroni corrected p-value: $\alpha / n=.05 / 3$ ). In the case of burglary, a significantly lower guilt rating was assigned when the suspect was female compared to male $(M=3.35$ versus $M=4.27$, respectively), $t(48)=-2.75, p<.01$. No significant gender differences were found within the fraud/forgery (female $M=4.01$ versus male $M=3.65$ ) or child abuse and neglect crime (female $M=3.88$ versus male $M=4.07$, respectively) categories.

Discussion

We tested whether varying levels of masculine physical appearance influenced perceptions of guilt and whether this influence differed for male versus female suspects. Additionally, the relationship between perceptions of guilt and masculine appearance was examined across three types of crimes, which differed according to whether they are viewed as being stereotypically male-perpetrated. The results indicated that individuals with a more masculine appearance were more likely to be perceived as guilty irrespective of the masculinity of the crime and gender of the suspect. Suspect gender, however, was found to affect guilt perceptions depending on crime type. Specifically, male suspects were given higher guilt ratings than female suspects for the crime of burglary, whereas female and male suspects were not rated differently for the crimes of fraud/forgery and child abuse and neglect. These results suggest that suspect gender, irrespective of masculine appearance, is influential with respect to perceptions of guilt if the crime in question is one that is deemed as being masculine in nature. Interestingly, people's ratings of the crime categories with respect to suspect gender were by and large in keeping with actual crime statistics: Burglary 
is largely committed by males, whereas there is less of a gender gap for the crimes of forgery and fraud, followed by child abuse and neglect (Flately, Kershaw, Smith, Chaplin, \& Moon, 2010; National Statistics Online, 2008).

The findings support the hypothesis that masculine physical appearance activates criminal stereotypes and thereby plays an influential role in person perception. The findings of the present study extend the results of Turner's (2007) study, in which individuals with a higher masculine appearance were more frequently identified as the perpetrator of the crime compared to individuals with a relatively low level of masculine appearance. We similarly found that a person is more likely to be viewed as guilty if they are more masculine in appearance. Furthermore, the results indicated that the relationship between masculine physical appearance and guilt holds for both male and female suspects. Quite possibly, the general population may have a tendency to believe that crime is largely committed by individuals who have an abundance of masculine physical features (Carlen, 1985), a view that was also espoused by early theorists in criminology. This belief, in turn, affects people's ground level assessments of guilt.

In relation to the nature of the crime and perceptions of guilt, other researchers (e.g., Shoemaker, et al., 1973; Macrae \& Shepherd, 1989) have found that suspect appearance affects guilt ratings depending on the type of crime committed. Our results extend this prior research. We found that the gender of the suspect affects perceptions of guilt depending on the type of crime in question. If the crime is one that is stereotypically committed by men more often than women (i.e., burglary), then the suspect was given higher guilt ratings if male rather than female. The results suggest that suspect gender is influential and separable to some degree from features that make faces appear excessively masculine. Evidence for 
this conclusion stems from our finding that male suspects, regardless of their masculinity level, were judged as guiltier than female suspects.

\section{Implications and Future Directions}

Future work may consider examining the influence of masculine physical appearance on mock jurors' perceptions of guilt, as well as legal officials charging recommendations and sentencing decisions. In the present study, participants were asked to rate the guilt of the stimuli in a somewhat impoverished context. Evidence of the suspect's guilt (or innocence) was not provided. Hence, the only information that could be used to rate the suspect's guilt was physical appearance. One possibility is that physical evidence could neutralise the biasing effect of suspect physical appearance on jury outcomes. However, criminal facial stereotypes have been found to be influential with respect to mock jury verdicts, regardless of the evidentiary strength of the case against the defendant (Dumas \& Teste, 2006). It is yet to be determined whether this would also hold true with respect to masculinity.

In relation to lineups, masculine appearance has been found to influence identification responses for male suspects (Turner, 2007). If the lineup is not fair because the suspect looks relatively more masculine than the other members, the odds of the suspect being identified increase. Other work has demonstrated that identification outcomes can be biased toward the suspects in real world police lineups if the suspect is more criminal looking than the lineup fillers (Flowe \& Humphries, 2010). To our knowledge, no studies have been conducted examining the relationship between criminal stereotypes and lineup identification outcomes for female suspects. Clearly further research with female suspects is warranted. 
Additional research is also needed to identify which physical features of faces give rise to perceptions of masculinity. Bustamante, et al. (2001), examined the specific features that were used to rate individuals as having a masculine physical appearance. These features included a large noses, eyebrows, and mouths. At present, however, it is unknown as to whether these features are attended to in forming guilt impressions. In the present study, the criminal appearance, attractiveness and the distinctiveness of the faces was held constant across the stimulus set. Consequently, the stimulus set for both genders differed significantly only in terms of criminal appearance. Previous research has demonstrated that faces rated high in criminal appearance are also rated as less attractive (e.g., Bull, 1979) and more distinctive (MacLin \& MacLin, 2004). In all likelihood, the relationship between guilt and masculine appearance would have been stronger had we allowed criminal appearance and attractiveness to also vary across the stimulus set.

\section{Conclusion}

Masculine physical appearance was found to influence perceptions of guilt. The relationship was found for both male and female suspects. Male suspects received higher guilt ratings than female suspects in the case of burglary, which is viewed stereotypically as a crime that is male-perpetrated. Future research regarding the role of masculinity and criminal stereotypes with respect to legal outcomes is needed, especially with female suspects. 


\section{References}

Bull, R. (1979). The influences of stereotypes on person identification. In D. P. Farrington, K. Hawkins, \& S. M. Lloyd-Bostock (Eds.), Psychology, law, and legal processes (pp. 184-194). London: Macmillan Press.

Bustamante, G., Herrera, V., \& MacLin, M. K. (April 2001). The masculinity-femininity link: Effects on mock witness identification of female targets. Poster presented at the Rocky Mountain Psychological Association Convention, Reno, NV.

Carlen, P. (1985). Introduction. In P. Carlen (Ed.), Criminal women (pp. 1-14). Cambridge: Polity Press.

Deffenbacher, K., Johanson, J., Vetter, T., \& O'Toole, A. J. (2000). The face typicalityrecognizability relationship: Encoding or retrieval locus? Memory and Cognition, 28, 1173-1182.

Dumas, R., \& Testé, B. (2006). The criminal facial stereotypes on juridic judgments. Swiss Journal of Psychology, 65, 237-244. doi: 10.1024/1421-0185.65.4.237

Flatley, J., Kershaw, C., Smith, K., Chaplin, R., \& Moon, D. (2010). Crime in England and Wales 2009/10. Home Office Statistical Bulletin. Retrieved from http://rds.homeoffice.gov.uk/rds/pdfs10/hosb1210.pdf

Flowe, H., \& Humphries, J. E. (2010). An examination of criminal face bias in a random sample of police lineups. Applied Cognitive Psychology, In press. doi: 10.1002/acp.1673

Herrington, V., \& Nee, C. (2005). Self-perceptions, masculinity and female offenders. Internet Journal of Criminology, 1-30. Retrieved from 
http://www.internetjournalofcriminology.com/Herrington $\% 20 \& \% 20 \mathrm{Nee} \% 20$ \%20Self-perceptions, $\% 20$ Masculinity $\% 20$ and $\% 20$ Female $\% 20$ Offenders.pdf

Hodgkiss, A., \& Handy, C. (2007). The criminal face effect: Physical attractiveness and character integrity as determinants of perceived criminality. Reinvention: A Journal of Undergraduate Research, Launch Issue. Retrieved from http://www.warwick.ac.uk/go/reinventionjournal/pastissues/launchissue/paper1

Kulka, R. A., \& Kessler, J. B. (1978). Is Justice Really Blind?-The Influence of Litigant Physical Attractiveness on Juridical Judgment. Journal of Applied Social Psychology, 8, 366-381. doi: doi:10.1111/j.1559-1816.1978.tb00790.x

National Statistics Online (2008). Crime. Retrieved from http://www.statistics.gov.uk/cci/nugget.asp?id=1661

Macrae, C. N., \& Shepherd, J. W. (1989). Stereotypes and social judgments. British Journal of Social Psychology, 28, 319-325.

Madriz, E. (1997). Nothing bad happens to good girls: Fear of crime in women's lives. Berkeley: University of California Press

MacLin, O. H., \& MacLin, K. M. (2004). The effect of criminality on face attractiveness, typicality, memorability and recognition. North American Journal of Psychology, 6, $145-154$

Mocan, H. N., \& Tekin, E. (2006). Ugly Criminals. Retrieved from $\mathrm{ftp}: / /$ repec.iza.org/RePEc/Discussionpaper/dp2048.pdf

O’Connor, M. E. (1984). The Perception of Crime and Criminality: The Violent Criminal and Swindler as Social Types. Deviant Behavior, 5, 255-274. 
Reed, J. P., \& Reed, R. S. (1973). Status, images, and consequence: Once a criminal always a criminal. Sociology and Social Research, 57(4), 460-472.

Saladin, M., Saper, Z., \& Breen, L. (1988). Perceived attractiveness and attributions of criminality: What is beautiful is not criminal. Canadian Journal of Criminology, 30, 251-159.

Sigall, H., \& Ostrove, N. (1975). Beautiful but dangerous: Effects of offender attractiveness and nature of the crime on juridic judgment. Journal of Personality and Social Psychology, 31, 410-414.

Shoemaker, D. J., South, D. R., \& Lowe, J. (1973). Facial stereotypes of deviants and judgments of guilt or innocence. Social Forces, 51, 427-433. doi: doi:10.2307/2576687

Skorinko, J. L., \& Spellman, B. A. (2006). Stereotypic crimes: How Group-Crime Associations Affect Memory and (sometimes) verdicts and sentencing. Retrieved from http://papers.ssrn.com/sol3/papers.cfm?abstract_id=917761

Stewart, J. E. (1980). Defendant's Attractiveness as a Factor in the Outcome of Criminal Trials: An Observational Study. Journal of Applied Social Psychology, 10, 348-361. doi: $10.1111 / j .1559-1816.1980 . t b 00715 . x$

Streib, V. L. (n.d). Death penalty for lesbians. Retrieved from http://www.cs.cmu.edu/afs/cs.cmu.edu/user/scotts/bulgarians/njsol/death_penalty_les bian.txt

Turner, N. (2007). Eyewitness perceptions: the effects of perceived likeability and masculinity on false identifications (Unpublished master's thesis). University of Portsmouth, Portsmouth, UK. 


$$
\frac{}{0^{3}}
$$


Table 1.

Participant $(N=20)$ Estimates of the Percentage of Crimes Committed by Males and Females as a Function of Criminal Offense Category.

\begin{tabular}{|c|c|c|}
\hline $\begin{array}{l}\text { Crime Category } \\
\text { Suspect Gender }\end{array}$ & Mean Percentage Estimated & SEM \\
\hline \multicolumn{3}{|l|}{ Robbery } \\
\hline Male & 72.70 & 10.98 \\
\hline Female & 31.10 & 17.63 \\
\hline \multicolumn{3}{|l|}{ Burglary } \\
\hline Male & 78.50 & 11.71 \\
\hline Female & 22.75 & 16.77 \\
\hline \multicolumn{3}{|l|}{ Rape } \\
\hline Male & 88.00 & 12.26 \\
\hline Female & 10.25 & 9.44 \\
\hline \multicolumn{3}{|l|}{ Prostitution } \\
\hline Male & 28.25 & 20.98 \\
\hline Female & 80.20 & 19.98 \\
\hline \multicolumn{3}{|c|}{ Child abuse and neglect } \\
\hline Male & 53.50 & 10.77 \\
\hline Female & 56.60 & 13.38 \\
\hline \multicolumn{3}{|l|}{ Drug offence } \\
\hline Male & 67.75 & 9.39 \\
\hline Female & 43.90 & 9.54 \\
\hline \multicolumn{3}{|l|}{ Domestic Violence } \\
\hline Male & 74.60 & 14.83 \\
\hline Female & 24.38 & 16.82 \\
\hline \multicolumn{3}{|l|}{ Fraud } \\
\hline Male & 64.25 & 17.04 \\
\hline Female & 42.50 & 17.36 \\
\hline \multicolumn{3}{|l|}{ Assault } \\
\hline Male & 75.75 & 9.60 \\
\hline Female & 33.00 & 15.20 \\
\hline \multicolumn{3}{|l|}{ Murder } \\
\hline Male & 72.65 & 11.70 \\
\hline Female & 29.60 & 15.29 \\
\hline
\end{tabular}




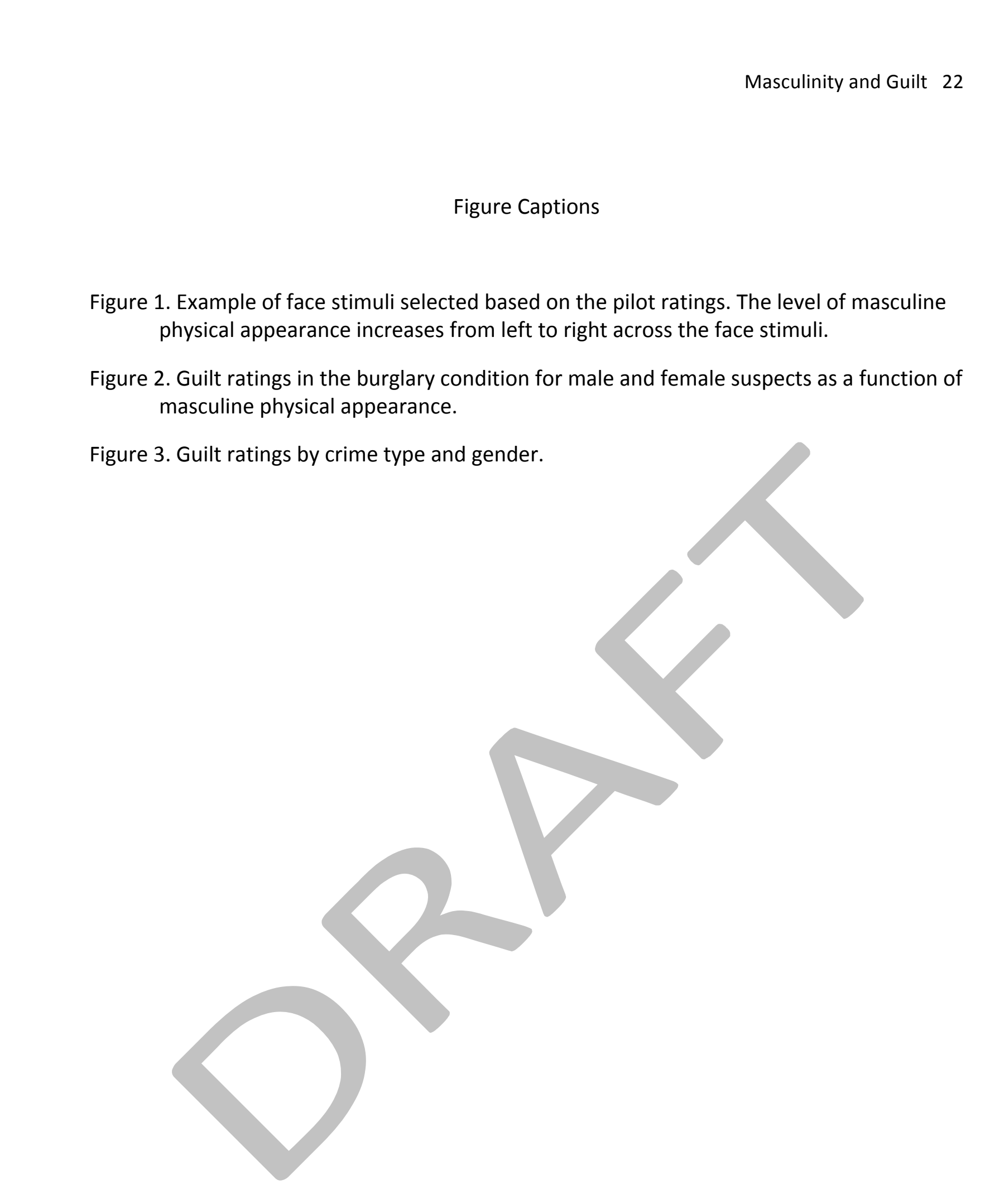


Masculinity and Guilt 23
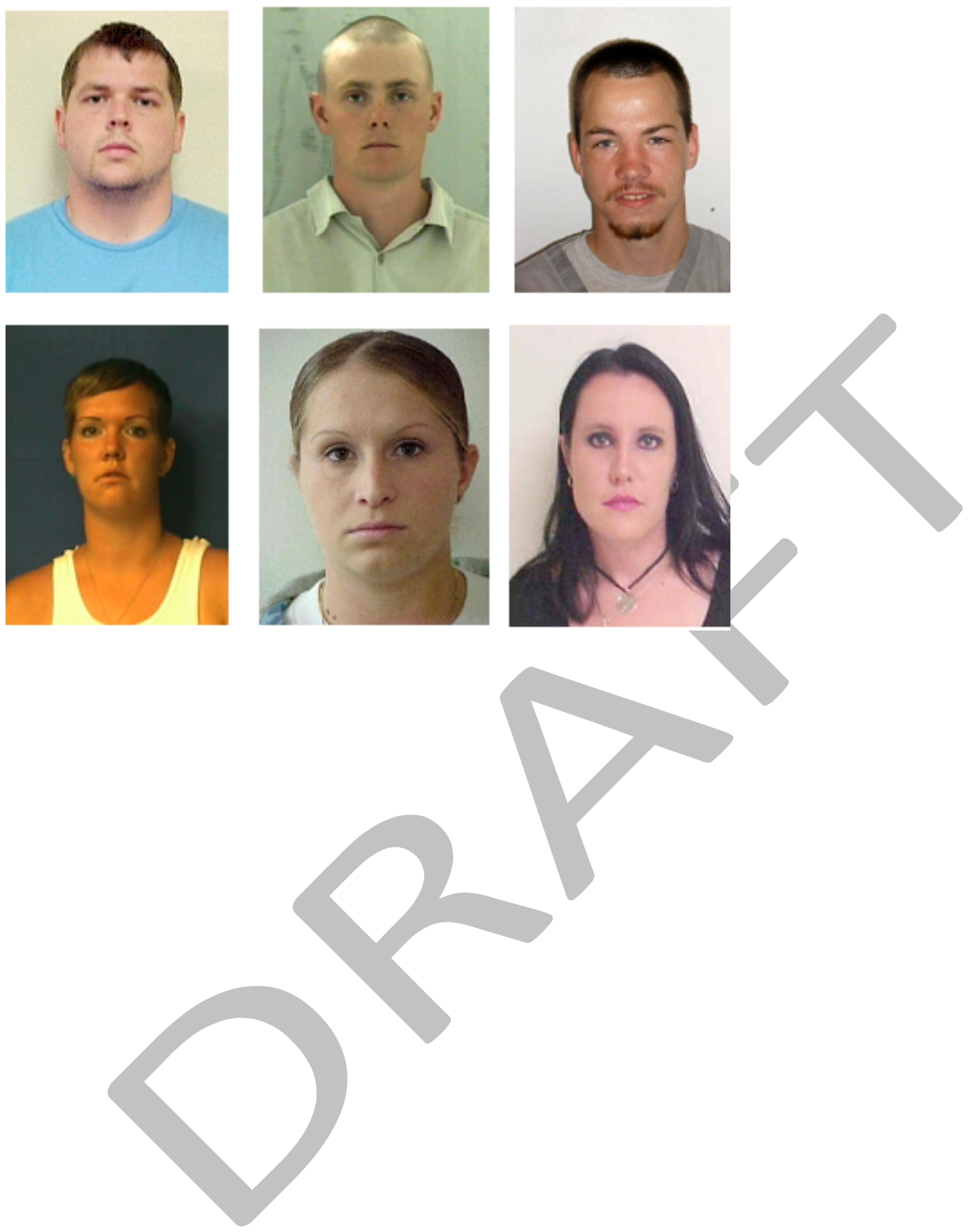
Figure 2

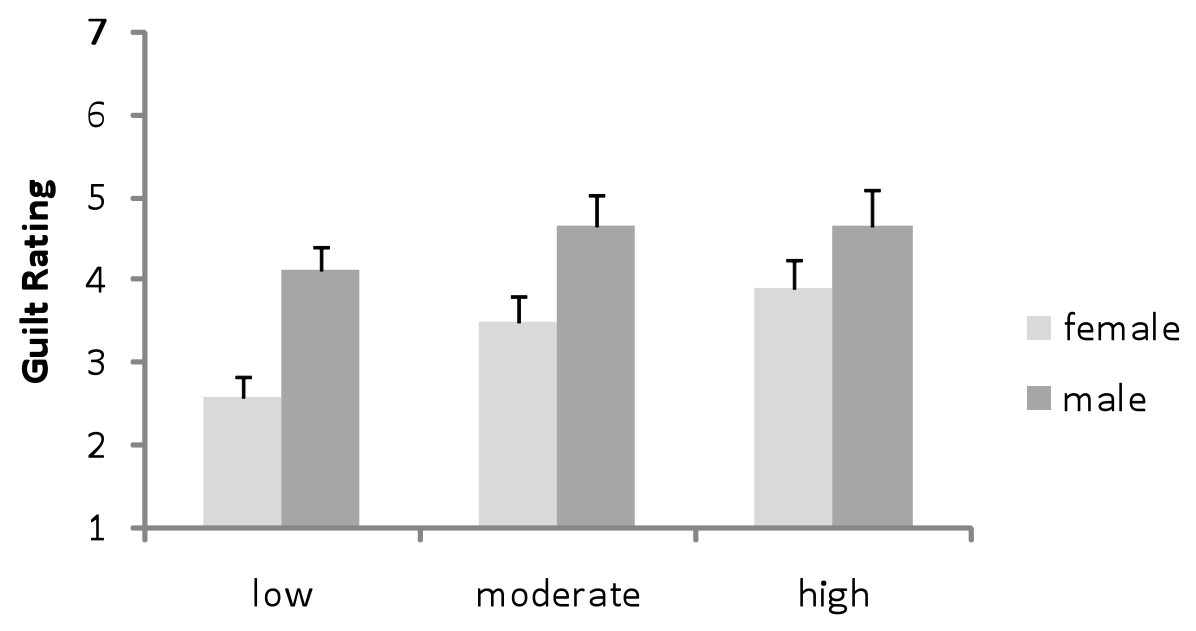

Masculine Appearance 